\title{
Effect of lactic acid fermented soyabean meal on the growth performance, intestinal microflora and morphology of weaned piglets*
}

\author{
N.F. Wang1, Q. Chen', G.W. Le ${ }^{2}$, Y.H. Shi ${ }^{2,3}$ and J. Sun ${ }^{1}$ \\ ${ }^{1}$ Key Laboratory of Food Science and Safety, Ministry of Education \\ Wuxi, Jiangsu, 214036, P.R. China \\ ${ }^{2}$ School of Food Science, Southern Yangtze University \\ No 170 huihe Road, Wuxi, Jiangsu, 214036, P.R. China
}

(Received 16 August 2006; accepted 2 February 2007)

\begin{abstract}
The aim of this study was to investigate the effects of lactic acid fermented soyabean meal (SBM) on the growth performance, intestinal microflora and morphology of weaned piglets. Lactic acid fermentation could reduce trypsin inhibitor activity and increase degree of protein hydrolysis in the fermented-SBM (FSBM). Seventy-two piglets weaned at $28 \pm 1 \mathrm{~d}$ of age were allotted to three dietary treatments for 28 days. The three diets were: 1 . diet with $25 \%$ SBM; 2 . diet with $20 \%$ SBM and $5 \%$ FSBM; 3 . diet with $15 \%$ SBM and 10\% FSBM. The results showed that the addition of $10 \%$ FSBM in the diet of piglets improved $(\mathrm{P}<0.05)$ the growth performance, increased $(\mathrm{P}<0.05)$ the numbers of intestinal lactobacilli, decreased $(\mathrm{P}<0.05)$ the numbers of intestinal enterobacteria and increased $(\mathrm{P}<0.05)$ the villus height and villus height to crypt depth ratio at the small intestinal mucosa compared to the control group. In conclusion, lactic acid fermented SBM can be used as an excellent protein source for weaned piglets.
\end{abstract}

KEY WORDS: piglets, fermented-soyabean meal, Lactobacillus plantarum, intestinal microflora, intestinal morphology, growth performance

\section{INTRODUCTION}

Piglets face many changes during the weaning transition. Abrupt changes in diet and environment make them more susceptible to potential enteric antigenic challenges (nutritional or microbial) during the post-weaning period, which can

\footnotetext{
* Supported by the PhD. Programs Foundation of Ministry of Education of China, Grant No. 20040295005

${ }^{3}$ Corresponding author: e-mail: yhshi06@163.com
} 
lead to impaired growth performance and high mortality (Brown et al., 2006). In order to improve the growth performance of piglets after weaning, animal protein sources, such as plasma protein, meat and bone meal, have been widely used in the diets of young animals because of their balanced amino acid composition, high protein digestibility and the absence of antinutritional factors compared to plant protein sources (Hong et al., 2004). However, the crisis of bovine spongiform encephalopathy led to a recent ban on the use of animal protein sources in the animal diets in Europe. Therefore, more suitable plant protein sources should be developed for piglets to help them overcome the problems with post-weaning and achieve the weaning transition in the shortest time possible.

SBM presents some undesirable characteristics which limit its use in newly weaned young animals. These include the presence of indigestible oligosaccharides, antinutritional factors and low protein digestibility. Various processing methods, such as heating, radiation, supplementation with enzymes and fermentation, have been used to improve the nutritional value of SBM. Among all the processing methods, fermentation has been reported to be a simple, cost-effective and efficient method to improve the nutritional value of SBM (Hong et al., 2004).

Many investigations have been carried out to improve the nutritional value of soya products by lactic acid fermentation. Lactic acid fermentation can reduce indigestible carbohydrates and antinutritional factors, and improve the protein digestibility and availability of amino acids of soya products (Refstie et al., 2005). Moreover, soya products fermented with lactic acid bacteria (LAB) can be looked as unique probiotic foods (Shimakawa et al., 2003). Therefore, SBM fermented with LAB may be an excellent protein source for newly weaned young animals.

The aim of this study was to investigate the use of SBM fermented with LAB in newly weaned piglets, by testing 1 . the effects of lactic acid fermentation on chemical and microbial compositions of SBM; 2. the effects of FSBM on the intestinal microflora and morphology of weaned piglets. In addition, the effect of FSBM on the growth performance of piglets was investigated.

\section{MATERIAL AND METHODS}

\section{Materials}

Lactobacillus plantarum NF8 was obtained from Dr. Jia L. (Shandong Agricultural University, Taian, China), which was isolated from pig faeces and identified by sequence analysis of the 16S rRNA. Prior to further use, L. plantarum NF8 was serially transferred three times in MRS broth and cultivated at $37^{\circ} \mathrm{C}$ for $18 \mathrm{~h}$. The suspension $\left(10^{9} \mathrm{CFU} / \mathrm{ml}\right)$ was used for further inoculation. 
Commercial defatted SBM (crud protein content $=47.62 \%$ ) was provided by Eastocean Cereals \& Oils Co., Ltd. (Zhangjiagang, China). Prior to further use SBM was cleaned and ground into flour to pass a 0.4-mm screen. All other reagents and chemicals used in this study were of analytical grade.

\section{Preparation of FSBM}

SBM flour, $0.5 \%(\mathrm{v} / \mathrm{w})$ of $L$. plantarum inoculum and distilled water in the amount to adjust moisture content of the mixtures to $50 \%$ were mixed in a food processor mixer (DW-25, Better Boiler Ltd., Shanghai, China). After thorough mixing, the mixtures were placed in hermetic flasks and incubated at $37^{\circ} \mathrm{C}$ for $72 \mathrm{~h}$. When the fermentation was completed, FSBM was freeze-dried.

\section{Chemical and microbial analysis of SBM and FSBM}

SBM and FSBM were sampled and used for microbial and chemical analysis. Dry matter and crude protein $(\mathrm{N} \times 6.25)$ contents of the samples were determined by the AOAC (1980) methods. The $\mathrm{pH}$ and titratable acidity (expressed as percent lactic acid) were determined according to the method described by Ikenebomeh (1989). The degree of protein hydrolysis in SBM and FSBM, defined as the percentage of peptide chain cleaved, was determined by an amino nitrogen analysis using trinitrobenzenesulphonic acid (Adler-Nissen, 1979). The content of trypsin inhibitor was measured according to the AOCS method (1995).

For bacterial enumeration, samples $(5.0 \mathrm{~g})$ were mixed with $45 \mathrm{ml}$ of $0.1 \%$ sterile peptone water followed by mixing homogeneously using a Labblender 400 stomacher (Seward Laboratory, London, UK). Then $0.1 \mathrm{ml}$ of appropriate dilutions was surface spread on MRS agar. The plates were incubated at $37^{\circ} \mathrm{C}$ for $48 \mathrm{~h}$ in an anaerobic cabinet (YQX-II, Cimo Medical Instrument Ltd., Shanghai, China) containing an anoxic atmosphere $\left(10 \% \mathrm{H}_{2}, 10 \% \mathrm{CO}_{2}, 80 \% \mathrm{~N}_{2}\right)$. Results were expressed as colony forming units per gram $(\mathrm{CFU} / \mathrm{g})$ of samples.

\section{Feeding trial}

Animals and feeding. Seventy-two piglets (Landrace $\times$ Yorkshire $\times$ Beijing Black) weaned at $28 \pm 1 \mathrm{~d}$ of age with an average initial body weight $(7.29 \pm 0.13$ $\mathrm{kg}$ ) were used in this experiment. Piglets were allotted to receive one of three dietary treatments on the basis of their litter origin, sex and body weight. Each treatment was replicated four times with six piglets per replicate. The three diets were: 1 . diet with $25 \%$ SBM (control); 2 . diet with $20 \%$ SBM and 5\% FSBM (LFSBM); 3. diet with 15\% SBM and 10\% FSBM (HFSBM). No antibiotic was 
included in diets. The dietary composition is presented in Table 1 . The experimental period lasted for 28 days. Feed and water were available ad libitum during the whole experiment. Feed intake was calculated daily and the animals were weighed weekly. The experimental protocol was approved by the Animal Care and Use Committee of Southern Yangtze University.

Table 1. Composition of experimental diets

\begin{tabular}{lccc}
\hline \multirow{2}{*}{ Item } & \multicolumn{3}{c}{ Diets } \\
\cline { 2 - 4 } & control & LFSBM $^{1}$ & HFSBM $^{1}$ \\
\hline Ingredients, \% & & & \\
ground maize & 58.5 & 58.5 & 58.5 \\
soyabean meal & 25.0 & 20.0 & 15.0 \\
fermented soyabean meal & - & 5.0 & 10.0 \\
fish meal & 6.0 & 6.0 & 6.0 \\
wheat bran & 3.0 & 3.0 & 3.0 \\
dried whey & 4.0 & 4.0 & 4.0 \\
salt & 0.3 & 0.3 & 0.3 \\
dicalcium phosphate & 1.1 & 1.1 & 1.1 \\
limestone & 0.9 & 0.9 & 0.9 \\
lysine & 0.2 & 0.2 & 0.2 \\
vitamin/trace mineral mix ${ }^{2}$ & 1.0 & 1.0 & 1.0 \\
Determined values & & & \\
digestible energy, MJ/kg & 14.05 & 14.02 & 13.97 \\
protein, \% & 19.78 & 19.81 & 19.83 \\
\hline
\end{tabular}

${ }^{1}$ LFSBM, low fermented-soyabean meal diet; HFSBM, high fermented-soyabean meal diet

${ }^{2}$ the vitamin-mineral mixture provided (per kg feed), IU: vit. A, 10000; vit. $\mathrm{D}_{3}$, 3000; vit. E, 30; mg: vit. $\mathrm{K}, 4$; vit. $\mathrm{B}_{1}$, 2; vit. $\mathrm{B}_{2}$, 6; pyridoxine, 4; cobalamin, 0.02 ; biotin, 0.12 ; folic acid, 1 ; niacin, 40; d-pantothenic acid, 12; Mn, 20; Zn, 220; Fe, 240; Cu, 180; I, 0.4; Co, 1.0; Se, 0.3

Sampling procedure. After the feeding trial, twelve piglets from each treatment were slaughtered under general anaesthesia and immediately eviscerated for samples collection. Samples of the contents from jejunum, caecum and colon were quantitatively collected into glass containers under $\mathrm{CO}_{2}$, sealed and put on ice until they were transported to the lab for microbial analysis. The specimens of intestinal tissue from the middle part of duodenum, jejunum and ileum segment were excised, flushed with physiological saline and fixed in $10 \%$ neutral-buffered formalin.

Enumeration of intestinal microbial populations. Bacteriological procedures were essentially the same as those described by Xia et al. (2005). Lactobacilli were enumerated on MRS agar after incubation in the anaerobic cabinet mentioned above at $37^{\circ} \mathrm{C}$ for $48 \mathrm{~h}$. Enterobacteria were enumerated on MacConkey agar after incubation at $37^{\circ} \mathrm{C}$ for $24 \mathrm{~h}$. For the enumeration of bifidobacteria, the diluted samples were spread on reinforced clostridial agar plus supplements (Munoa and 
Pares, 1988), and incubated in the anaerobic cabinet at $37^{\circ} \mathrm{C}$ for $72 \mathrm{~h}$. Subsequently, the bacteria were identified to genus level on the basis of colonial appearance, gram reaction, spore production, cell morphology and fermentation end-product formation.

Histomorphometry. Methods for assessing the intestinal tissue morphology were based on those described by Xu et al. (2003). Three cross-sections for each intestinal sample were prepared after staining with haematoxylin and eosin using standard paraffin embedding procedures. A total of 10 intact, well-oriented cryptvillus units were selected in triplicate for each intestinal cross-section. Villus height and crypt depth were determined using a computerized image analysis system (Leica Q500MC, Leica Cambridge Ltd., Cambridge, UK).

\section{Statistical analysis}

Results are expressed as means and standard deviation. Data were analysed by one-way analysis of variance (ANOVA) using SPSS version 11.5 (SPSS, Chicago, IL, USA). Differences were considered statistically significant at $\mathrm{P}<0.05$.

\section{RESULTS}

\section{Chemical and microbial compositions of SBM and FSBM}

The chemical and microbial compositions of SBM and FSBM are shown in Table 2. The unfermented SBM contained a very small population of LAB. After

Table 2. Chemical and microbial composition of soyabean meal (SBM) and fermented-soyabean meal (FSBM)

\begin{tabular}{lrr}
\hline Item & \multicolumn{1}{c}{ SBM } & \multicolumn{1}{c}{ FSBM } \\
\hline $\mathrm{pH}$ & $6.59 \pm 0.05^{\mathrm{a}}$ & $3.83 \pm 0.01^{\mathrm{b}}$ \\
Dry matter, \% & $89.46 \pm 0.05^{\mathrm{a}}$ & $91.12 \pm 0.07^{\mathrm{b}}$ \\
Titratable acidity ${ }^{\mathrm{a}} \%$ & $0.56 \pm 0.02^{\mathrm{a}}$ & $6.15 \pm 0.01^{\mathrm{b}}$ \\
Lactic acid bacteria, log CFU/g & $3.34 \pm 0.51^{\mathrm{a}}$ & $8.92 \pm 0.27^{\mathrm{b}}$ \\
Crude protein, \% & $47.62 \pm 0.07^{\mathrm{a}}$ & $53.78 \pm 0.05^{\mathrm{b}}$ \\
Degree of hydrolysis, \% & $1.38 \pm 0.03^{\mathrm{a}}$ & $10.80 \pm 0.04^{\mathrm{b}}$ \\
Trypsin inhibitors, mg/g & $3.12 \pm 0.02^{\mathrm{a}}$ & $0.54 \pm 0.03^{\mathrm{b}}$ \\
\hline
\end{tabular}

${ }^{1}$ titratable acidity was expressed as percent of lactic acid

${ }^{a, b}$ mean within rows without a common superscript differ significantly $(\mathrm{P}<0.05)$

fermentation with $L$. plantarum NF8, viable counts of LAB increased to $8.92 \mathrm{log}$ $\mathrm{CFU} / \mathrm{g}$ in FSBM and titratable acidity increased to $6.15 \%$. The $\mathrm{pH}$ was reduced from nearly neutral to 3.83 after fermentation. As shown in Table 2, there was a 
significant increase in total protein content and degree of protein hydrolysis in FSBM compared to SBM. Lactic acid fermentation also resulted in a significant reduction of trypsin inhibitor content in FSBM. The content of trypsin inhibitor was reduced from 3.12 to $0.54 \mathrm{mg} / \mathrm{g}$ after fermentation.

\section{Piglet-feeding studies}

Intestinal microflora. The numbers of total lactobacilli, enterobacteria and bifidobacteria in the intestinal tract of the piglets fed the three experimental diets are shown in Figure 1. A significant increase $(\mathrm{P}<0.05)$ was observed in the numbers of lactobacilli in the intestinal tract of the piglets fed the HFSBM diet compared to the control group, while the numbers of enterobacteria decreased significantly $(\mathrm{P}<0.05)$. The numbers of bifidobacteria in the intestinal tract of piglets were not significantly affected by the experimental diets, although a tendency to increase $(\mathrm{P}>0.05)$ was observed in the piglets fed the LFSBM and HFSBM diets compared to the control group.

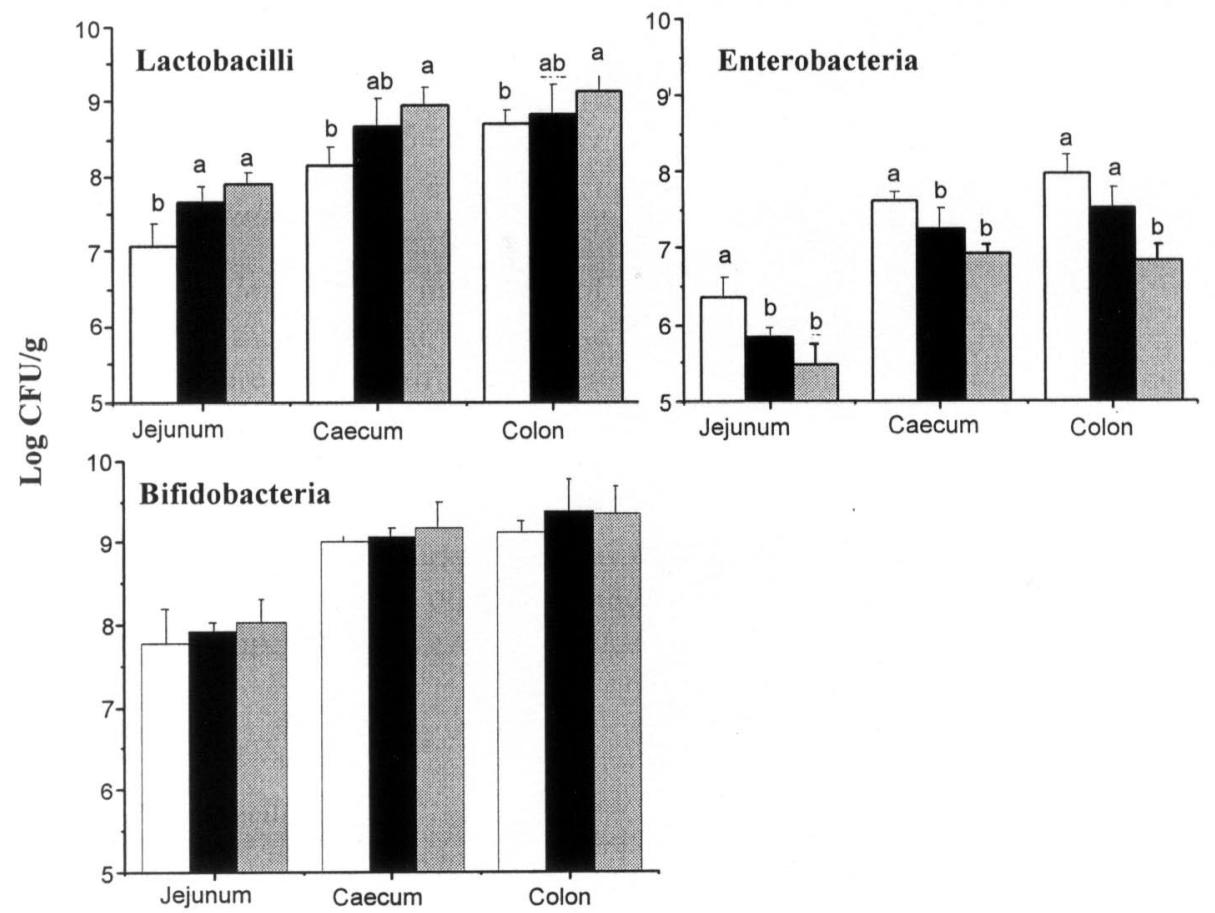

Figure 1. Effect of diets ( $\square$ control; - LFSBM; - HFSBM) on the numbers of lactobacilli, enterobacteria and bifidobacteria in the content from jejunum, caecum and colon of piglets $(n=12)$. Bacterial numbers are expressed as $\log \mathrm{CFU} / \mathrm{g}$ of digesta, wet basis. Treatments with different superscript letters on bars differ significantly $(\mathrm{P}<0.05)$. LFSBM (low fermented-soyabean meal diet); HFSBM (high fermented-soyabean meal diet) 

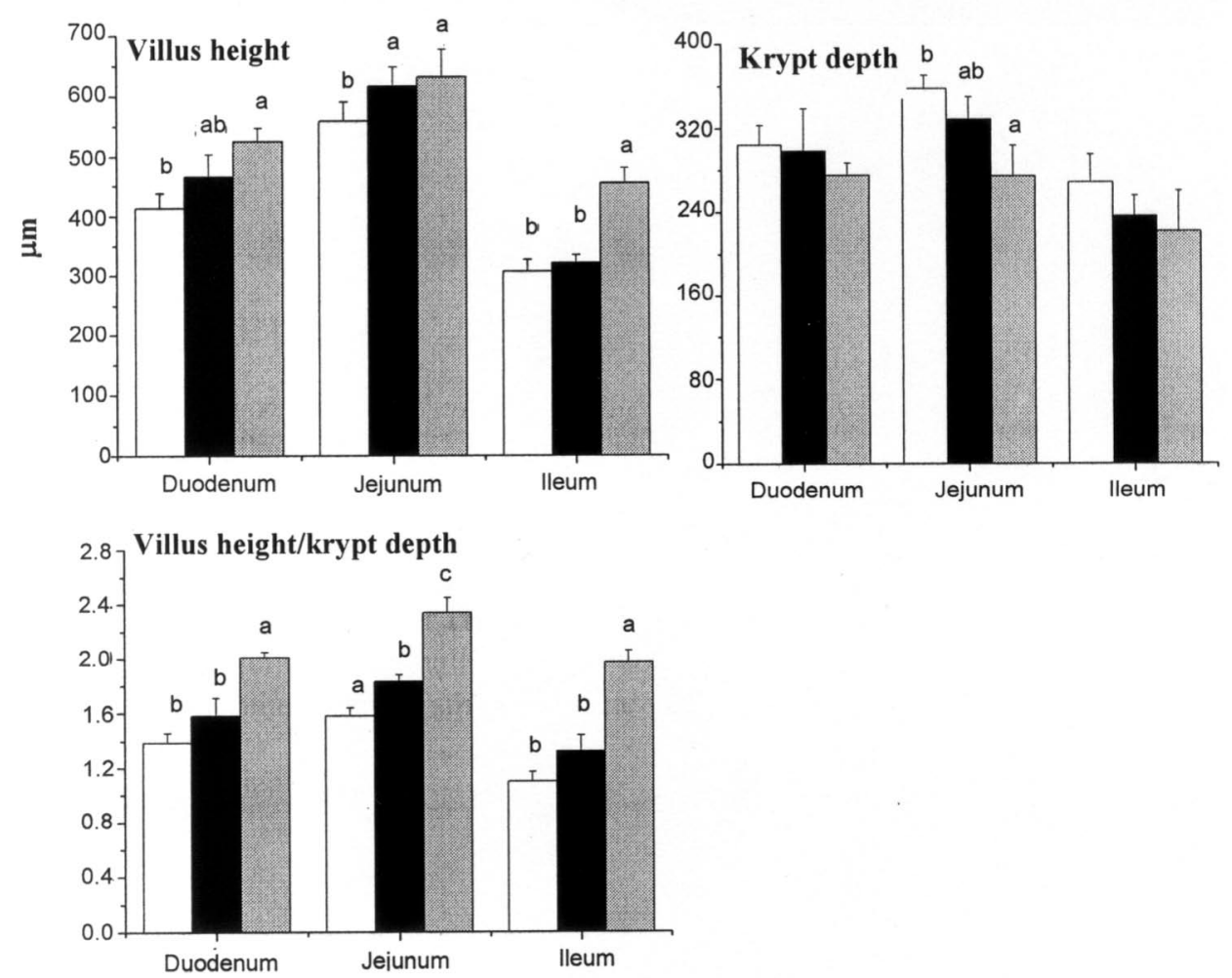

Figure 2. Effect of diets ( $\square$ control; — LFSBM; $\square$ HFSBM) on the morphology of the intestinal mucosa at different sites of the small intestine $(\mathrm{n}=12)$. Treatments with different superscript letters on bars differ significantly $(\mathrm{P}<0.05)$. LFSBM (low fermented-soyabean meal diet); HFSBM (high fermented-soyabean meal diet)

Morphology of the small intestinal mucosa. Morphology data for the duodenum, jejunum, and ileum are presented in Figure 2. Piglets fed the HFSBM diet had higher $(\mathrm{P}<0.05)$ villus height and villus height to crypt depth ratio in the small intestine compared to the control group. In addition, the crypt depth was lower in the jejunum of piglets fed the HFSBM diet compared to the control group. Piglets fed the LFSBM diet had higher $(\mathrm{P}<0.05)$ villus height and villus height to crypt depth ratio in the jejunum of small intestine compared to the control group, while the differences in other parts of small intestine were not significant $(\mathrm{P}>0.05)$.

Growth performance. The addition of FSBM into the diets had a positive effect on growth performance of weaned piglets (Table 3). Average daily gain $(\mathrm{ADG})$ and average daily feed intake $(\mathrm{ADFI})$ were higher $(\mathrm{P}<0.05)$ in piglets fed the HFSBM diet compared to piglets fed the control diet. Piglets fed LFSBM diet tended to have higher growth rate and feed intake than those fed the control 
Table 3. Effect of fermented-soyabean meal (FSBM) supplementation on growth performance of piglets

\begin{tabular}{|c|c|c|c|}
\hline \multirow{2}{*}{ Item } & \multicolumn{3}{|c|}{ Diets } \\
\hline & control & LFSBM $^{1}$ & HFSBM $^{1}$ \\
\hline Initial weight, kg & $7.29 \pm 0.11$ & $7.28 \pm 0.09$ & $7.29 \pm 0.13$ \\
\hline Final weight, kg & $14.08 \pm 0.53^{\mathrm{a}}$ & $14.74 \pm 0.65^{\mathrm{a}}$ & $15.64 \pm 0.41^{b}$ \\
\hline $\mathrm{ADG}^{2}, \mathrm{~g}$ & $252.3 \pm 10.5^{\mathrm{a}}$ & $271.6 \pm 16.5^{\mathrm{a}}$ & $305.9 \pm 12.7^{b}$ \\
\hline $\mathrm{ADFI}^{2}, \mathrm{~g}$ & $493.5 \pm 28.4^{b}$ & $516.9 \pm 22.8^{\mathrm{ab}}$ & $558.3 \pm 31.8^{\mathrm{a}}$ \\
\hline $\mathrm{F} / \mathrm{G}$ & $2.01 \pm 0.15^{\mathrm{a}}$ & $1.94 \pm 0.07^{\mathrm{a}}$ & $1.85 \pm 0.06^{b}$ \\
\hline
\end{tabular}

${ }^{1}$ LFSBM, low fermented-soyabean meal diet; HFSBM, high fermented-soyabean meal diet ${ }^{2} \mathrm{ADG}$, average daily gain; ADFI, average daily feed intake; $\mathrm{F} / \mathrm{G}$, feed-to-gain ratio

${ }^{\mathrm{a}, \mathrm{b}}$ mean within rows without a common superscript differ significantly $(\mathrm{P}<0.05)$

diet, but the differences were not significant $(\mathrm{P}>0.05)$. The feed-to-gain ratio $(\mathrm{F} / \mathrm{G})$ of piglets fed the HFSBM diet was significantly improved $(\mathrm{P}<0.05)$ when compared to those fed the control and LFSBM diets.

\section{DISCUSSION}

It has been widely reported that the enzymatic and secretory functions in the gastrointestinal tract of weaning piglets may not be fully functional and lack efficiency in degrading plant-based substrates (Mathew et al., 1996). The presence of antinutritional factors and complex structure of protein in SBM limit its use in weaned piglets. Protein hydrolysates have been reported as more suitable protein sources for animal and human nutrition, because of their digestion and absorption in the gastrointestinal tract are more effective than intact protein (Ziegler et al., 1990). In the present study, the content of trypsin inhibitor decreased to $0.54 \mathrm{mg} / \mathrm{g}$ after fermentation, which is lower than $0.77 \mathrm{mg} / \mathrm{g}$ that can reduce the growth performance of pigs (Hong et al., 2004). At the same time, the degree of protein hydrolysis was improved. Proteins in FSBM were hydrolysed into peptides, even free amino acids, which could be easily digested and absorbed by young animals.

Probiotics are live microbial feed or food supplements, which beneficially affect the host by improving its intestinal microbial balance. To exert their beneficial effects on the host, probiotic products should contain at least $6 \log$ CFU live microorganism per $\mathrm{g}$ or per $\mathrm{ml}$ at the time of consumption (Shimakawa et al., 2003). The viable count (8.92 log CFU/g) of LAB in FSBM was significantly higher than this criterion, indicating that FSBM might be a unique probiotic feed for piglets. In the present study, FSBM was dehydrated by freeze-drying. Although it allows nutritional value of FSBM to be highly retained, freeze-drying 
is a more expensive technique than other conventional methods of drying. Wang et al. (2004) investigated the viability of LAB in fermented soyamilk after freezedrying and spray-drying. Although the viable counts in spray-dried soyamilk were higher than $6 \log \mathrm{CFU} / \mathrm{g}$, they were significantly lower than those in freeze-dried soyamilk. The high temperature during the spray-drying process could reduce the viability of LAB. Further studies are needed to develop economical drying methods which can substitute freeze-drying, together with high viability of LAB after drying.

In the pathogenesis of post-weaning diarrhoea of weaned piglets, enteropathogenic Escherichia coli strains play a major role. Fermented feeds can reduce the number of coliforms in the gastrointestinal tract of pigs (Van Winsen et al., 2001), and then the risk of post-weaning diarrhoea could be reduced. This in turn would improve the growth rate and feed efficiency of piglets. From our results, a significant increase in the numbers of lactobacilli was observed in the intestinal tract of piglets fed HFSBM diet compared to control group. At the same time, the numbers of enterobacteria decreased significantly. These could be considered beneficial to the intestinal microbial balance. The large numbers of $\mathrm{LAB}$, high concentration of lactic acid and several volatile fatty acids and the low $\mathrm{pH}$ representing the most important characteristics of FSBM, may play an essential role in improving the microbial balance of gastrointestinal tract.

However, many studies reported that fermented feeds have no significant effect on the number of LAB throughout the gastrointestinal tract of pigs (Donnet-Hughes et al., 1999; Demeckova et al., 2002). Moreover, contrast to our findings, Canibe and Jensen (2003) found a lower count of LAB in the caecum and mid-colon of pigs fed fermented liquid feed compared to those fed dry feed or not fermented liquid feed. This could be explained by a reduction of available substrates for microbial fermentation in these segments of gastrointestinal tract after feeding fermented liquid feed. The difference between their studies and ours is their results are based on research with completely fermented compound diets rather than on research with diets to which fermented ingredients were added.

The weaning transition of piglets is often accompanied by villus shortening and crypt deepening in the small intestine. These changes can lead to poor nutrient absorption, reduced disease resistance and growth performance. In the present study, addition of FSBM could increase the villus height and villus height to crypt depth ratio in the small intestine of the weaned piglets. These results were agree with the findings of other studies in which positive effects on intestinal villus height and villus height to crypt depth ratio were observed in pigs fed fermented feeds (Nousiainen, 1991; Scholten et al., 2002). There are many factors that may be involved in the changes in the structure of the gastrointestinal tract. One factor may be related to the presence of short-chain fatty acids. Nousiainen (1991) 
reported that villus height in piglets is positively correlated with contents of shortchain fatty acids in the intestinal lumen. Another factor is the reduction of the number of coliforms in the gastrointestinal tract. Coliforms can produce toxic amines and ammonia, which are harmful for the gastrointestinal mucosa (Scholten et al., 1999).

Fermentation is a complex process and variety of chemical and microbial changes have taken place during the fermentation. Besides the mechanisms mentioned above, there may be other mechanisms which can stimulate the growth performance of piglets. For example, Refstie et al. (2005) reported that lactic acid fermentation could reduce the indigestible carbohydrates in SBM and improve lipid digestibility in Atlantic salmon. More studies are needed to elucidate the effects of lactic acid fermented SBM on the weaning piglets, which will stimulate more successful application of lactic acid fermented SBM in pig nutrition.

\section{CONCLUSIONS}

The results obtained in present study indicated that the addition of FSBM in the diet of weaned piglets have a positive effect on the intestinal microbial balance, increase significantly the villus height and villus height to crypt depth ratio in the small intestine, and stimulate the growth performance. In conclusion, lactic acid fermented SBM can be used as an excellent protein source for newly weaned piglets.

\section{ACKNOWLEDGEMENTS}

The authors would like to thank Zhu J.J. and Li Y.F. for their technical assistance with the experiments.

\section{REFERENCES}

Adler-Nissen J., 1979. Determination of the degree of hydrolysis of food protein hydrolysates by trinitrobenzenesulfonic acid. J. Agr. Food Chem. 27, 1256-1262

AOAC, 1980. Official Methods of Analysis, Association of Official Analytical Chemists. $13^{\text {th }}$ Edition. Washington, DC

AOCS, 1995. Official Methods and Tentative Practices of the American Oil Chemists, American Oil Chemists' Society. $5^{\text {th }}$ Edition. Champaign, IL

Brown D.C., Maxwell C.V., Erf G.F., Davis M.E., Singh S., Johnson Z.B., 2006. The influence of different management systems and age on intestinal morphology, immune cell numbers and mucin production from goblet cells in post-weaning pigs. Vet. Immunol. Immunopathol. 111, 187-198 
Canibe N., Jensen B.B., 2003. Fermented and nonfermented liquid feed to growing pigs: effect on aspects of gastrointestinal ecology and growth performance. J. Anim. Sci. 81, 2019-2031

Demeckova V., Kelly D., Coutts A.G.P., Brooks P.H., Campbell A., 2002. The effect of fermented liquid feeding on the faecal microbiology and colostrum quality of farrowing sows. Int. J. Food Microbiol. 79, 85-97

Donnet-Hughes A., Rochat F., Serrant P., Aeschlimann J.M., Schiffrin E.J., 1999. Modulation of nonspecific mechanisms of defence by lactic acid bacteria: effective dose. J. Dairy Sci. 82, 863-869

Hong K.J., Lee C.H., Kim S.W., 2004. Aspergillus oryzae GB-107 fermentation improve nutritional quality of food soybeans and feed soybean meals. J. Med. Food 7, 430-435

Ikenebomeh M.J., 1989. The influence of salt and temperature on the natural fermentation of African locust bean. Int. J. Food Microbiol. 8, 133-139

Mathew A.G., Franklin M.A., Upchurch W.G., Chattin S.E., 1996. Influence of weaning age on ileal microflora and fermentation acids in young pigs. Nutr. Res. 16, 817-827

Munoa F.J., Pares R., 1988. Selective medium for the isolation and enumeration of Bifidobacterium spp. Appl. Environ. Microbiol. 54, 1715-1718

Nousiainen J., 1991. Comparative observations on selected probiotics and olaquindox used as feed additives for piglets around weaning. 2. Effect on villus height and crypt depth in the jejunum, ileum, caecum and colon. J. Anim. Physiol. Anim. Nutr. 66, 224-230

Refstie S., Sahlstrom S., Brathen E., Baeverfjord G., Krogedal P., 2005. Lactic acid fermentation eliminates indigestible carbohydrates and antinutritional factors in soybean meal for Atlantic salmon (Salmo salar). Aquaculture 246, 331-345

Scholten R.H.J., van der Peet-Schwering C.M.C., den Hartog L.A., Balk M., Schrama J.W., Verstegen M.W.A., 2002. Fermented wheat in liquid diets: Effects on gastrointestinal characteristics in weanling piglets. J. Anim. Sci. 80, 1179-1186

Scholten R.H.J., van der Peet-Schwering C.M.C., Verstegen M.W.A., den Hartog L.A., Schrama J.W., Vesseur P.C., 1999. Fermented co-products and fermented compound diets for pigs: a review. Anim. Feed Sci. Tech. 82, 1-19

Shimakawa Y., Matsubara S., Yuki N., Ikeda M., Ishikawa F., 2003. Evaluation of Bifidobacterium breve strain Yakult-fermented soymilk as a probiotic food. Int. J. Food Microbiol. 81, 131-136

Van Winsen R.L., Urlings B.A.P., Lipman L.J.A., Snijders J.M.A., Keuzenkamp D., Verheijden J.H.M., van Knapen F., 2001. Effect of fermented feed on the microbial population of the gastrointestinal tracts of pigs. Appl. Environ. Microbiol. 67, 3071-3076

Wang Y.C., Yu R.C., Chou C.C., 2004. Viability of lactic acid bacteria and bifidobacteria in fermented soymilk after drying, subsequent rehydration and storage. Int. J. Food Microbiol. 93, 209-217

Xia M.S., Hu C.H., Xu Z.R., 2005. Effects of copper bearing montmorillonite on the growth performance, intestinal microflora and morphology of weanling pigs. Anim. Feed Sci. Tech. $118,307-317$

Xu Z.R., Hu C.H., Xia M.S., Zhan X.A., Wang M.Q., 2003. Effects of dietary fructooligosaccharide on digestive enzyme activities, intestinal microflora and morphology of male broilers. Poultry Sci. 82, 648-654

Ziegler F., Ollivier J.M., Cynober L., Masinin J.P., Coudray-Lucas C., Levis E., Giboudeau J., 1990. Efficiency of enteral nitrogen support in surgical patients: small peptides vs. non-degraded proteins. Gut 31, 1277-1283 